rev.relac.int.estrateg.segur.8(1):189-205,2013

\title{
EL RESURGIMIENTO DE LOS TALIBANES EN AFGANISTÁN*
}

\section{Angélica Alba Cuéllar*}

\section{RESUMEN}

Este artículo revisa las dinámicas propias del fenómeno talibán y de su resurgimiento como una fuerza indiscutida y altamente resistente en Afganistán. Persiguiendo el objetivo de restablecer su versión extremista del Islam en el país, el movimiento talibán ha desplegado una violencia difícilmente controlable que contribuye a mantener el clima de inestabilidad y desafía la capacidad del gobierno de ejercer eficazmente su autoridad, todo ello enmarcado en un contexto político y de seguridad estructuralmente complejo.

Palabras clave: fragmentación étnica, movilización pashtún, injerencia externa, inestabilidad.

* Artículo de reflexión. Línea de investigación en Análisis de conflictos internacionales. Grupo de Política y Relaciones Internacionales. Registro en Colciencias COL0041319. Centro Clacso.

** Internacionalista de la Universidad del Rosario, Magíster en Análisis de problemas políticos, económicos e internacionales del Instituto de Altos Estudios para el Desarrollo del Ministerio de Relaciones Exteriores y la Universidad Externado de Colombia. Profesora de tiempo completo del Programa de Relaciones Internacionales de la Universidad Jorge Tadeo Lozano. angelicaj.albac@utadeo.edu.co 


\title{
THE REAPPEARANCE OF THE TALIBANS IN AFGHANISTAN
}

\begin{abstract}
This article reviews the dynamics of the Taliban phenomenon and its resurgence as an undeniable force and a highly resistant movement in Afghanistan. Pursuing the objective of restoring their extremist version of Islam in the country, the Taliban group has displayed a widespread violence that contributes to maintain the instability and challenges the government's ability to effectively exercise its authority, all these framed in a structurally complex political and security context.
\end{abstract}

Keywords: Ethnic fragmentation, Pashtun mobilization, foreign interference, instability.

\section{O RESSURGIMENTO DO TALIBÃ NO AFEGANISTÃO}

\section{RESUMO}

Este artigo analisa a dinâmica do fenômeno Talibã e seu ressurgimento como uma força incontestável e como um movimento de alta resistência no Afeganistão. Com o objetivo de restaurar uma versão extremista do Islã no país, o Talibã tem implantado uma violência incontrolável que contribui para a manutenção de um clima de instabilidade e desafia a capacidade do governo de exercer eficazmente a sua autoridade, tudo isso emoldurado em um contexto político e de segurança estruturalmente complexo.

Palavras-chave: Fragmentação étnica, movimento pashtun, interferência externa, instabilidade.

\section{INTRODUCCIÓN}

Ubicado en el corazón de Asia y en la encrucijada entre Irán, Asia Central, el mar Arábigo y la India, Afganistán es un Estado que ha sido sometido a diversas presiones, tanto endógenas como exógenas, que lo han forzado históricamente a límites inimaginables y que siguen teniendo profundos efectos sobre la gobernabilidad, la seguridad y, principalmente, sobre el bienestar de la nación afgana.

Establecido como Estado en 1747, Afganistán había sido parte de grandes imperios y centro de una cultura y economía prósperas desde épocas remotas. Sin embargo, más recientemente y en más de una ocasión, ha servido como estado tapón entre ideologías y poderes rivales. En el siglo XIX, el país se convirtió en el epicentro del denominado 'Gran Juego' entre los británicos y los rusos en su competencia por lograr influencia en la región. Tras la imposición de los primeros, el país permanecería bajo la influencia británica hasta $1919^{2}$. 
Pero a pesar de caracterizarse por un fiero sentimiento de independencia y orgullo que ha hecho complejos los esfuerzos de grandes potencias por dominar el país, el pueblo afgano es uno muy heterogéneo y de compleja composición, lo que constituye un elemento crucial a la hora de plantear las causas de la conflictividad del país. Además de estar dividido en varias etnias, la fuerte estructura tribal y de clanes ha hecho de esta una sociedad esencialmente fragmentada, en cuyos marcos se han desarrollado unos modos de vida y dinámicas políticas, pero en la que se evidencia la ausencia de un patrón unificador nacional. Es dentro de esta lógica que terminó imponiéndose en los noventas la visión extremista de los talibanes, cuyo resurgimiento y creciente influencia contribuyen a explicar la persistencia de la inestabilidad y la conflictividad en el país.

\section{LA COMPLEJIDAD AFGANA}

Afganistán es uno de los Estados más fragmentados del mundo desde el punto de vista étnico. En principio, existe una diferenciación general entre los pashtunes ${ }^{3}$, mayoritarios, y los no pashtunes, bien sea por cuestiones de lengua o diferencias culturales. Sin embargo, el país cuenta con cerca de 25 grupos étnicos diferenciados, de los cuales los más representativos, además de los pashtunes, son los tayikos, los uzbekos y los hazaras ${ }^{4}$

No hay duda acerca del peso que los pashtunes han tenido histórica y políticamente en el país, lo que permite afirmar que quien logra movilizar a los pashtunes logra gobernar a Afganistán. Entre 1747 y 1973, el país estuvo regido por una monarquía cuyas dinastías fueron pashtunes, de la tribu de los durrani ${ }^{5}$. Sin embargo, ese último año un golpe de Estado proclamó la República, y cinco años más tarde, en la llamada 'Revolución Saur', el presidente Mohammed Daoud fue asesinado, instaurándose un gobierno comunista. Estos hechos contribuyeron al rompimiento de un delicado equilibrio que, basado en la estratégica distribución de los recursos y el respeto

1. El interés principal de los rusos y luego de los soviéticos era la búsqueda de una salida terrestre hacia el Océano Indico, es decir, a las aguas calientes. Gran Bretaña se opuso consistentemente, pues temía que la influencia rusa en la región amenazara su posición en la India.

2. Los británicos impusieron la denominada Línea Durand en 1893. Se trata de un trazado de 2640 km que tenía con fin establecer los límites occidentales de la India y atravesaba las áreas tribales de los pashtunes, por lo que fueron divididos entre Afganistán y el futuro Pakistán.

3. Los pashtunes son una etnia de origen indoeuropeo, cuya lengua es el pashto. La mayor parte son musulmanes sunitas.

4. Los uzbekos y los turkmenos se identifican por su lengua (ambos son turcófonos). Los hazaras se distinguen en general por su filiación chí́ta, aunque hay una minoría hazara sunita, cuya lengua es el dari, una variante del persa. Los Tajikos son más complejos de identificar, pues entran en una categoría residual determinada por los afganos, en la que se incluyó a los pueblos de habla dari que no eran parte de los hazaras. Éstos son mayoritariamente sunitas.

5. Los pashtunes se dividen en varios grupos tribales, dominados en el país por dos confederaciones principales que han luchado en ocasiones entre sí: los durrani (del que Hamid Karzai es miembro) y los ghilzai (a la que pertenecen buena parte de los talibanes). 
por las prerrogativas de las elites locales bajo el predominio pashtún, permitía que un Estado precario como Afganistán pudiese sobrevivir (Maley, 2002:7).

El nuevo gobierno comunista establecido en el país tuvo que enfrentar muy pronto un levantamiento interno que ponía en peligro su supervivencia, lo que forzó la intervención de la Unión Soviética. Este hecho convirtió a Afganistán en un escenario clave de disputa en la guerra fría y generó una dinámica interna tremendamente conflictiva, pues la invasión produjo una resistencia afgana, que aunque poco cohesionada, pudo unirse por el flujo de ayuda a la causa de los denominados mujahideenes y logró mantener una guerra de guerrillas en oposición a los invasores. Durante ese periodo, los estadounidenses, paquistaníes y saudíes intentaron proporcionar a los mujahideenes mejores armas y estimularlos para formar un gobierno interino. Tras una larga lucha, el repliegue del Ejército Rojo en 1989 produjo una gran euforia entre ellos y sus seguidores, pero no estableció de ningún modo las bases para la pacificación del país.

La situación se tornó en una guerra en contra el régimen comunista de Mohammed Najibullah, que aunque siguió contando con el apoyo encubierto de Moscú, finalmente cayó en 1992. Los mujahideenes acordaron compartir el poder en un esquema de presidencia rotativa; en ese sentido, es destacable que con el gobierno liderado por el tayiko Burhanudin Rabbani se rompió la lógica tradicional del ejercicio del poder en el país, pues era la primera vez que un no pashtún había logrado establecer un gobierno con apoyo de otras minorías étnicas. Sin embargo, este sistema no funcionó y algunas facciones se volcaron a la lógica del combate, liderada por señores de la guerra como Abdul Rashid Dostum, Ismail Khan y Gulbuddin Hekmatyar, que sometieron al país nuevamente a la anarquía, y cuyo epicentro fue la capital del país.

\section{EL SURGIMIENTO DLOS TALIBANES}

El caos fue el rasgo más característico de Afganistán hasta que los talibanes, animados por la rabia popular frente a los caóticos efectos de la guerra entre las facciones, emergieron en el verano de 1994. Estos talib o estudiantes, ubicados principalmente en la frontera con Pakistán, incluían algunos de los mujahideenes de facciones como el Hezb-e Islami y del Harakat, que lucharon contra los soviéticos en los años ochenta. Sin embargo, la mayor parte de los estudiantes de estas madrazas paquistaníes eran muy jóvenes para haber combatido contra la URSS, por lo que el movimiento se nutrió principalmente de huérfanos de los campos de refugiados reclutados por las escuelas, es decir, víctimas y no combatientes de la guerra. Así los talibanes, inicialmente un grupo de estudiantes con poco entrenamiento militar, configuraron un movimiento que llegó a controlar el $90 \%$ del país en menos de 5 años.

Es necesario anotar que antes del triunfo de los talibanes, ninguna secta o movimiento fundamentalista había encontrado asiento ni tenido una influencia destacada en el país. Pero 
este movimiento logró despojar de su poder a los señores de la guerra que habían fraccionado el territorio y el dominio del país -con excepción de la organización de Ahmad Shah Massoud, el León de Panjshir-, imponiendo una suerte de poder unificado, inexistente desde 1979, basado en una interpretación anómala del Islam, emergida de las madrazas deobandis ${ }^{6}$ de Pakistán, de crucial importancia en el proceso. Los deobandis predican una forma de ortodoxia conservadora en la que el mal y la apostasía pueden ser definidos en parte como el alejamiento de los rituales (Maley, 2002, p. 15), y que busca la regeneración de la sociedad musulmana por medio de la aplicación de los principios coránicos en rechazo de toda idea de progreso político o económico, y de las costumbres puras predicadas por Mahoma. Estas ideas se fundieron con algunos elementos del wahabismo, dando paso a la creación de una visión del Islam muy particular que se transmitió en las madrazas dirigidas entonces por mullahs apenas alfabetos que promovieron una nueva forma de extremismo religioso, producto sin duda de su mínimo contacto con los debates islámicos alrededor del mundo. El Mullah Omar, antiguo combatiente frente a los soviéticos, se identificó de manera importante con esta ideología y la adoptaría como propia del movimiento en proceso de formación.

Se dice que de los 30 combatientes que iniciaron actividades, sólo 14 tenían armas (Davis, 2002, p. 44), por lo que resulta evidente la existencia de un importante apoyo externo al movimiento -esencialmente ayuda militar proveniente de Pakistán y financiamiento saudí-. Pero, ¿cómo lograron los talibanes movilizar a sectores de la sociedad afgana, especialmente a los pashtunes? Esto puede explicarse por la existencia de un conjunto de condiciones internas del país, caracterizadas por el vacío de poder, las luchas étnicas y el cansancio de la sociedad afgana frente a los constantes conflictos. Además, los talibanes fueron capaces de hacer a un lado a varios líderes pashtunes, minando su apoyo popular y acercándose a las bases (Crews et.al., 2008, p. 61), se unieron a ellos algunos khalquis, excomunistas que adhirieron motivados por la solidaridad étnica, y lograron atraer a pashtunes moderados, que pensaban que podían lograr así el retorno de Zahir Shah, el monarca derrocado en 1973.

\section{EL PAPEL DE TERCEROS PAÍSES}

Durante el periodo de la yihad contra los soviéticos, los Estados Unidos fungieron como patrones de la resistencia, pues temían que la URSS pudiera amenazar el flujo de petróleo proveniente del Golfo Pérsico. Sin embargo, tras la retirada del Ejército Rojo en 1989, los norteamericanos también abandonaron al país. Washington nunca desarrolló, tras el fin de la Guerra Fría, un marco estratégico para la región, y más bien dejó entrever su reluctancia a involucrarse en un escenario tan complejo (Rashid, 1999, p. 35). Así que tras el fin de la ocupación, Los Estados

6. El término deobandi se deriva de la ciudad de Deoband, en la India, en donde se estableció un instituto en 1867, cuyas ideas han sido muy influyentes en Afganistán. 
Unidos dejaron en manos de sus aliados en la región, Pakistán y Arabia Saudí, los asuntos por venir en el contexto de la guerra civil, mientras los conflictos entre los líderes locales lo hacían uno de los lugares más hostiles en el mundo.

La política de Pakistán hacia Afganistán desde el tiempo de la invasión soviética, se caracterizaba por un 'clientelismo étnico transfronterizo' (Saikal, 2002, p. 37), consecuencia de la existencia de una sustancial minoría pashtún en ese país, y razón por la cual Pakistán siempre había pretendido desarrollar una influencia significativa en la política afgana. Islamabad adoptó una tendencia claramente propashtún, otorgando importante ayuda a los grupos de resistencia predominantemente pashtunes, principalmente al Hezb-e Islami de Hekmatyar. Cuando Benazir Bhutto volvió a ser Primera Ministra de Pakistán en 1993, nombró como su Ministro del Interior y consejero en asuntos afganos al general retirado Naseerullah Babar, quien para muchos merece el título de 'padrino' de los talibanes (Maley, 1998, p. 219). Bhutto quería un Afganistán "libre de facciones", lo que en la práctica significaba que deseaba que la facción propaquistaní eliminara a otras que detentaban cierto poder en el país.

El general Babar, un pashtún con un amplio conocimiento de la dinámica en la frontera, estuvo involucrado desde el comienzo con las actividades de los talibanes en Afganistán. Si bien es cierto que las figuras claves del movimiento eran afganas y éste en muchos sentidos se cimentaba sobre las bases que localmente habían tenido grupos poco exitosos como el Hezb, se trató de una manifestación de la injerencia de un país más fuerte contra la integridad territorial y la independencia política de otro débil, de manera encubierta y a través de sustitutos (Maley, 1998, p. 221), en este caso a través de los servicios de inteligencia paquistaníes -ISI-, que tenían relaciones bien establecidas en la región de Kandahar, lugar en donde pronto las fuerzas talibanes empezaron a desarrollar sus actividades.

En este sentido, resulta fundamental apreciar el alcance de la incidencia paquistaní en el proceso de formación y crecimiento de los talibanes. Además de lo anotado, es necesario resaltar que una gran cantidad de los talibanes que lucharon en el país provenían de Pakistán; aunque no fueron los únicos extranjeros que se unieron al talibán, su apoyo era de lejos el más importante, y entre 1994 y 1999, un estimado de 80.000 a 100.000 paquistaníes se entrenaron y combatieron en Afganistán (Rashid, 1999, p. 27). Esta penetración obedeció además al interés de Pakistán de lograr una mayor profundidad geográfica y estratégica en el evento de una guerra convencional con la India; para los paquistaníes, el apoyo al talibán podía proveer de un conjunto de extremistas dispuestos a atacar a los indios en Cachemira y en otros lugares, mientras se prevenía que se estableciera un gobierno proindio en Kabul (O'Hanlon, 2010, p. 22). También se argumentan preocupaciones económicas, especialmente relacionadas con la rentabilidad que podían generar los oleoductos y gasoductos desde el Asia Central al Asia del Sur a través de un Afganistán estable bajo un posible régimen talibán, y cuestiones étnicas, referentes a la necesidad de un país gobernado nuevamente por pashtunes (Maley, 1998, p. 222). 


\section{EL ÉXITO DE LOS TALIBANES}

Los talibanes hicieron su primera gran aparición en la escena afgana en el momento en el que las facciones y movimientos más grandes combatían entre sí por el control de Kabul. En 1994, sus fuerzas empezaron a ganar terreno en regiones estratégicas como Kandahar, en donde establecieron su capital, y ganaron el apoyo popular al desarmar a otras bandas e imponer una estricta disciplina en varias regiones. Paulatinamente, extendieron su control sobre otras zonas, especialmente las pashtunes, que les permitieron convertirse en la principal fuerza militar del país, al tiempo que eliminaban los bloqueos de los caminos, iniciaban la aplicación de la sharia, cerraban las escuelas para niñas y establecían una unidad que tenía raros precedentes en la región (Sinno, 2008, p. 64). Pero es claro que los talibanes tampoco eran representativos de las complejidades sociales afganas; era un grupo abrumadoramente pashtún y suní, en general hostil a otras etnias y a los chiíes en el país, que además omitía la moderación en la aplicación de los códigos religiosos y tribales.

Los miembros del talibán que tomaron Kabul en septiembre de 1996 eran, para entonces, más que meros estudiantes religiosos; ya constituían una fuerza militar por nombre propio, el "Movimiento Islámico Talibán". Su emergencia y arribo al poder es uno de los hechos más inesperados en la historia reciente y sus principios de gobierno uno de los más extraños que el mundo moderno presenciaría, esencialmente por su naturaleza antimoderna. Hasta la captura de Kabul, los talibanes no había expresado una clara intención de gobernar el país; sin embargo, a partir de ese momento, respaldados por Arabia Saudí y Pakistán, e inspirados por mentores ideológicos como bin Laden, los combatientes talibanes se comprometieron en la conquista de Afganistán (Rashid, 1998, p. 24).

Para explicar su emergencia, los miembros del movimiento afirmaban que el Mullah Muhammad Omar había tenido un sueño en el que se le llamaba a liderar una campaña de los estudiantes 'puros' para limpiar a Afganistán de la corrupción y la depravación de los señores de la guerra (Maley, 1998, p. 220). Es evidente que este 'sueño' tiene todos los rasgos de un mito fundacional que buscaba legitimar una fuerza que tomó forma para otros propósitos. Sin embargo, el Mullah Omar no era un líder especialmente carismático con las masas; poco elocuente, era sin duda respetado por su piedad por los líderes máximos del movimiento. Tomó el título de 'Emir de los fieles', por lo que los talibanes renombraron al país 'Emirato Islámico de Afganistán', remarcando el establecimiento de una autoridad absoluta, negando la repartición del poder, e incluso repudiando la política. Inicialmente, el Mullah Omar era aconsejado por la Shura Suprema, conformada por otros mullahs; pero con el paso del tiempo, el proceso de toma de decisiones se fue haciendo menos claro y más excluyente (Maley, 1998, p. 224). Incluso se dice que Osama bin Laden y otros árabes lo aconsejaban en cuestiones de política exterior $-y$ en algunas decisiones de carácter 
doméstico, como la destrucción de los Budas de Bamiyán-, al igual que lo hacían algunos funcionarios del ISI paquistaní.

No obstante, y a pesar de su triunfo, tres centros principales de poder quedaron fuera del control talibán: uno al noreste, ocupado por las fuerzas de Massoud tras su retirada de Kabul; el segundo, la región de Hazarajat; y el tercero, el feudo de Rashid Dostam en Mazar-e Sharif. En esos territorios se afincaban las fuerzas opositoras al movimiento; finalmente, la unión de las fuerzas de Dostam, Massoud, Rabbani y del líder chiita Karim Khalili, dio origen a la llamada Alianza del Norte, compuesta principalmente por uzbekos, tayikos y hazaras, que liderados por Massoud, tenían como fin urgente detener y derrotar al talibán.

Tras la toma de Kabul, otros países profundizaron su apoyo a otras facciones antitalibán y al aún reconocido gobierno de Rabbani: Rusia, Irán e India, además de cuatro ex repúblicas soviéticas en el Asia Central, se unieron para presionar diplomáticamente a Pakistán y disuadir a la comunidad internacional de reconocer al régimen. Pakistán solo pudo atraer a Arabia Saudí y a los Emiratos Árabes Unidos para que reconocieran diplomáticamente al talibán, mientras que Glyn Davies, portavoz del Departamento de Estado, afirmó en el momento que "los Estados Unidos no encuentran nada objetable en las declaraciones políticas del nuevo gobierno, incluyendo su intención de imponer la ley islámica" (Gasper, P., 2001). Tal posición frente a la instauración de un gobierno fundamentalista vinculado con el cultivo y tráfico de drogas era inusual; sin embargo, el lobby de firmas que esperaban transportar recursos energéticos desde Turkmenistán a Pakistán vía Afganistán, así como el hecho de que el régimen era opuesto al iraní, podían explicar esta postura (Maley, 2002, p. 3). De hecho, llama la atención que cuando los talibanes capturaron Kabul, algunos ejecutivos de Union Oil Company of California -Unocal-creyeron que la construcción de un oleoducto se iba a ejecutar más fácilmente (Rashid, 2002, p. 166).

Entre 1997 y 1998, el régimen logró avances fundamentales en el norte del país en medio de los combates con facciones enemigas, especialmente enconados contra los hazaras chítas. Las fuerzas de Massoud ${ }^{8}$ permanecieron durante buena parte del periodo de 1996 a 2001 cerca de Kabul; sin embargo, para el inicio del nuevo siglo, sólo las regiones del noroeste de la capital, el Valle del Panshjir y otras áreas cercanas, estaban fuera del control talibán, lo que constituía cerca de un 10\% del territorio. El apoyo encubierto de Pakistán fue clave en esta expansión de los talibanes como una fuerza regional y nacional; no obstante, el apoyo económico de Arabia Saudí se mantuvo solo hasta ese último año, cuando los líderes de los talibanes dejaron claro que no iban a dejar de proteger a Osama bin Laden, que les proporcionaba importantes recursos para su ejército.

7. El islam empezó a expandirse a través de Afganistán poco después de la muerte de Mahoma en 632. Sin embargo, algunas regiones como Kabul y el centro y sur del país siguieron siendo budistas hasta el siglo XII, cuando fueron conquistadas por gobernantes musulmanes, o convertidas.

8. Fue asesinado el 9 de septiembre de 2001 por miembros de al Qaeda que se hicieron pasar por periodistas belgas. 


\section{LAS RAZONES DEL TRIUNFO TALIBÁN}

Como se ha mencionado, además de la ayuda externa, la existencia de unas complejas condiciones internas se sumó a las razones que explican el éxito talibán en Afganistán. De una parte, sus fuerzas pudieron llenar rápidamente el vacío de poder existente en el sur del país, partiendo de la base de la etnicidad compartida con los pashtunes en sus áreas de control, en su énfasis en la piedad religiosa y en el cansancio de la población frente a la guerra. Muchos afganos dieron la bienvenida al talibán debido a su hincapié en la necesidad de instaurar la ley y el orden: la seguridad era un tema fundamental, así como la garantía de estabilidad a través de la aplicación de la ley islámica. No hay duda de que muchos afganos recibieron de buena gana esta promesa de seguridad, por ejemplo los traficantes de drogas (Maley, 1998, p. 233); pero ésta, sin duda, estaba basada más en el miedo que en el imperio de la ley.

Oliver Roy se refiere al fenómeno talibán como una clara expresión de lo que denomina 'neofundamentalismo', en el que se recalca la importancia que el grupo le otorga a la aplicación de la sharia y no al establecimiento de un estado islámico (Roy, 2003). Eran, antes que nada, antimodernistas, lo que se evidencia en su aproximación a la política; eran más un movimiento que un partido, y ello resultaba en una relativa debilidad en el proceso de implementación de decisiones. Por ello, en vez de ver la ley islámica como un complejo de tradiciones sujetas a interpretación y evolución, los talibanes la asumían como un rígido código de reglas y castigos a ser aplicados. No reconocían una esfera de la vida privada, que estaba entonces siempre al alcance de las autoridades del movimiento, mientras que el 'Emirato Islámico', como un protoestado, estaba precariamente definido (Maley, 1998, p. 235). El mensaje de que no debe existir coacción en la religión, contenido en el Corán, no tenía resonancia entre el liderazgo, y pronto la dureza de su gobierno transformó la esperanza en disgusto y miedo.

La dependencia de ejecución de la ley era la policía religiosa, responsable de la 'promoción de la virtud y supresión del vicio', una de las mejor organizadas pero también una de las más perversas agencias del régimen. El liderazgo asumía que las ciudades como Kabul eran ciudades del pecado, que debían ser gobernadas con mano dura, mientras las áreas rurales, especialmente pobladas por pashtunes, les representaban menos interés, pues se sentían más seguros allí. Las mujeres, que habían podido circular libremente por la capital durante cuatro décadas y constituían la mayor parte del cuerpo de estudiantes de la Universidad de Kabul, ahora se veían confinadas a sus casas y tan sólo podían abandonarlas usando la burqa. Los hombres debían usar barbas, se prohibió la música, los juegos de mesa, elevar cometas, las palomas mensajeras... (Maley, 2002, p. 1) sin embargo, y a pesar del férreo control de la mayor parte de los aspectos de la vida pública y privada de los afganos, los líderes no eran capaces, por ejemplo, de manejar la moneda del país, y dirigían una suerte de economía criminalizada basada principalmente en actividades ilícitas como la explotación del tránsito comercial, el contrabando entre Afganistán y Pakistán y el tráfico del opio, del cual el país se convirtió en el mayor productor mundial bajo su régimen. 
La creciente visibilidad y atención suscitada por los talibanes antes del 11 de septiembre de 2001 van a ser consecuencia de su radicalismo extremo, materializado en su falta de apego a los Derechos Humanos, en especial en el trato hacia las mujeres, y en acciones como la destrucción de los Budas de Bamiyán. No obstante, es el hecho de que el país sirviera de santuario para las actividades de al Qaeda lo que marcaría el fin del régimen del Mullah Omar.

\section{EL DERROCAMIENTO DEL RÉGIMEN}

Tras los atentados del 11 de septiembre de 2001, atribuidos a bin Laden y su red al Qaeda, era predecible que parte de la responsabilidad terminara recayendo sobre el gobierno talibán en Kabul, protector de los terroristas. Bush urgió a sus líderes a entregar a Osama bin Laden o sufrir las consecuencias; éstos respondieron que Osama era un musulmán que había luchado la yihad contra los soviéticos y que entregarlo violaría, además, el código de hospitalidad pashtún.

Hacia fines de ese mes, Bush había aprobado el apoyo encubierto a las fuerzas antitalibán y una pequeña misión militar dominada por los Estados Unidos trabajó con la Alianza del Norte y otros grupos de resistencia para derrocar al régimen ${ }^{9}$. Massoud había favorecido el orden institucional más que un gobierno patrimonial, así que a pesar de su muerte días antes de los atentados terroristas, los Estados Unidos aún podían contar con un aliado en el terreno que más ahora que antes estaba dispuesto a cooperar. Además, Washington persiguió una estrategia de aislamiento internacional del grupo.

El 7 de octubre, la coalición liderada por los Estados Unidos lanzó la operación 'Libertad Duradera', minando la posición del régimen y atacando a los combatientes de al Qaeda en Afganistán. Antes de ese momento, se estima que las fuerzas talibanes contaban con cerca de $30.000 \mathrm{hom}$ bres (O'Hanlon, 2010, p. 22); pero a medida que perdían batallas, y tras la toma de Kabul por parte de la Alianza del Norte, muchos combatientes detuvieron su apoyo al movimiento, y buena parte de sus líderes, junto con miembros de al Qaeda, viajaron a las cercanas regiones tribales y montañosas de Pakistán. Por lo tanto, este era el país que resultaba más importante alinear en la aplicación de la estrategia norteamericana. Poco antes de estos hechos, Pervez Musharraf había criticado a los grupos extremistas por generar condiciones que minaban la imagen internacional del país frente a la inversión y la seguridad, poniendo de relieve los problemas de Pakistán para lidiar con el terrorismo. Por ello, frente a la presión del presidente Bush a Islamabad para declararse abiertamente como su amigo -o su enemigo- en el nuevo contexto

9. El Frente Unido estaba conformado por grupos como Shura-ye Nezar, Jamiat-e Islami, Shura-ye Mashreqi, Wahdate Islami, y Jombush-e Melli, representando en general a los grupos religiosos y étnicos del país. 
de la Guerra Mundial contra el Terrorismo, el presidente Musharraf declaró el firme apoyo de su país a los Estados Unidos y se convirtió en el aliado clave para el desarrollo de las operaciones de la coalición en la región.

Buena parte de los talibanes se dispersaron en ciudades pequeñas y áreas residenciales en donde se camuflaron entre la población y el régimen fue derrotado rápidamente. Esto obedeció a una combinación de varios factores: la pérdida del apoyo paquistaní, con la afectación de su fuerza militar, y la falta de legitimidad del movimiento dentro del país. Sin embargo, y a pesar de los triunfos iniciales, la victoria militar absoluta era prácticamente imposible; por ello, ya en esos días era evidente que resultaba necesario, por parte de la coalición, establecer una estrategia más amplia para hacer frente a los reductos talibanes.

\section{EL NUEVO GOBIERNO AFGANO Y EL RETO DE LA SEGURIDAD}

Mientras la base de poder de los talibanes colapsaba, la atención internacional y local se enfocó en la reconstrucción del país. En la conferencia de Bonn en diciembre de 2001, a la que no fueron invitados los talibanes, Hamid Karzai, un pashtún moderado, fue elegido el líder interino del país. Esta elección fue bien recibida por la mayoría de los afganos y por muchos países, y a partir de ella se intentó conformar un gabinete representativo de la heterogeneidad étnica del país. Karzai, que incluso declaró una amnistía general para todas las fuerzas, se esforzó por establecer una distinción entre "Ios talibanes ordinarios, que son hijos reales y honestos de su país", y aquellos que "aún utilizan la cubierta de los talibanes para perturbar la paz y la seguridad en el país" (Crews, et.al, 2008, p. 279). Los miembros de la Alianza del Norte, parte sustancial del nuevo gobierno del país, rechazaron duramente esta posición, que podría desafiar su naciente autoridad.

La debilidad del nuevo régimen sería palmaria precozmente, pues a las dificultades naturales que enfrentaba un gobierno de transición, se sumó el hecho de que éste contaba con muy poca gente capacitada y limitados recursos para generar las condiciones de seguridad y bienestar para los afganos; además, el interés de los Estados Unidos se centraba en seguir trabajando con los señores de la guerra para continuar golpeando a al Qaeda, minimizando a la vez las posibilidades del gobierno central de fortalecerse (O'Hanlon, 2010, p. 22). En enero de 2004, la nueva constitución, redactada por la Comisión Constitucional Afgana, fue aprobada por la Loya Yirga, la asamblea tradicional, y más tarde, ese mismo año, Karzai fue elegido presidente del país, a pesar de los esfuerzos de los talibanes y de otras agrupaciones de atacar a los candidatos. En septiembre de 2005, los afganos eligieron un nuevo parlamento, que incluyó a algunos ex ministros talibanes; sin embargo, y a pesar de los esfuerzos, la insurgencia, conformada principalmente por reductos talibanes, contribuyó decididamente al deterioro de la ya difícil situación general del país. 


\section{EL RESURGIMIENTO DE LOS TALIBANES}

En la primavera y el verano de 2002, mientras terminaban las acciones más importantes de la Operación Anaconda ${ }^{10}$, facciones talibanes y otras fuerzas insurgentes como al Qaeda y el Hizbe Islami, empezaron a desarrollar acciones ofensivas con el fin de desestabilizar al gobierno afgano, disuadir el despliegue de fuerzas internacionales en la misión de paz y forzar eventualmente a los Estados Unidos y las tropas de la coalición a retirarse del país. Por tanto, la seguridad ha sido la preocupación principal del gobierno afgano desde el periodo de la transición. Las acciones de la insurgencia talibán, la más importante del país, han consistido en ataques terroristas con explosivos principalmente en el sur y el sureste del país, e incluso han ejecutado algunas decapitaciones que han despertado el terror entre la población. Sin embargo, son los atentados suicidas, inéditos en Afganistán, los que mayor impacto han generado. Antes del 11$S$ eran un arma desconocida en la larga historia de conflictos en el país; sin embargo, y debido a la influencia y asistencia de al Qaeda, han ganado terreno de manera vertiginosa, aunque se cree que son ejecutados principalmente por extranjeros.

La reemergencia de los talibanes como una agrupación aún más compleja obedece a varios factores: el restablecimiento del apoyo logístico proveniente del exterior, el retorno de los combatientes extranjeros, y el financiamiento procedente del tráfico de drogas son quizás los más significativos. El movimiento opera como un grupo disperso de células de entre cinco y veinticinco hombres que cruzan regularmente la porosa frontera afgano-paquistaní para llevar a cabo sus acciones terroristas (Karzai, 2006, p. 63). Para 2005, se estimaba que operaban con unidades de cerca de cien hombres, y en el 2008 actuaban tanto con unidades de batalla como con unidades pequeñas (Jones, 2008, p. 51). Aunque comprenden que no pueden enfrentar la fuerza de las tropas de la coalición, los talibanes han ejecutado una estrategia de ataque a blancos 'suaves', como trabajadores humanitarios, empleados del gobierno y civiles. Han recuperado y mejorado progresivamente su capacidad militar, lo que les ha permitido pretender el restablecimiento de su gobierno, y ha sido crucial el soporte de su viejo aliado Jamiat-e-Ulema Islam, el partido político paquistaní estrechamente ligado al movimiento deobandi centrado en las zonas pashtunes de Pakistán. Además, paradójicamente, han encontrado en el uso de los medios masivos y la tecnología una manera eficaz de promover sus ideas y objetivos, principalmente en sitios web yihadistas.

Precisamente, una de las características más interesantes del proceso de reagrupamiento y resurgimiento talibán es la apelación al discurso yihadista para lograr restablecer su control sobre el país. Al parecer, en febrero de 2003 el Mullah Omar emitió una fatwa en la que proclamaba que cerca de 1600 prominentes estudiosos de todo Afganistán acordaron que era un deber de todo musulmán emprender la yihad (Crews et.al, 2008, p. 297), y las redes de apoyo yihadista

10. Se denominó así a la mayor batalla convencional en el marco de la Operación Libertad Duradera.

EL RESURGIMIENTO DE LOS TALIBANES EN AFGANISTÁN 
han contribuido a hacer más letales los ataques contra las fuerzas afganas y de la coalición. Además, la inclusión de nuevos miembros, conocidos como neotalibanes ${ }^{11}$, que siguen siendo reclutados en madrazas y villas en Afganistán y Pakistán, han evolucionado más allá del régimen original para abarcar nuevos grupos con nuevas agendas (Jones, 2008, p. 39); algunos de ellos autodenominados mujahideenes, añaden más confusión al ya complejo intento de definir la misión y la identidad de la insurgencia.

La ideología de estos llamados neotalibanes se basa aún en la legitimidad que reclaman para su causa como procedente de la voluntad divina; sin embargo, no se trata de un bloque homogéneo y coherente. Algunos están alineados con los 'al Qadeistas' y las ideas adoptadas por el Mullah Omar y los talibanes más radicales en la época final del régimen, mientras que otros parecen haber vuelto a sus tradicionales raíces pashtunes y tratan de convertirse en los voceros, no solo de la etnia, sino de los musulmanes tradicionalistas en el país (Crews et.al, 2008, p. 306). Se presume que tras la invasión de Irak y el esfuerzo de bin Laden de enviar más apoyo a los insurgentes allí, la visión predominante ha sido, desde 2004, la de los tradicionalistas. No obstante, incluso los combatientes de las nuevas generaciones mantienen un respeto importante hacia el Mullah Omar, pues es cierto que ningún otro líder hoy ha podido desafiar su influencia y simbolismo en el movimiento.

La voluntad de las autoridades en ciudades como Kandahar de permitir a los ex líderes de los talibanes retornar a sus casas y ciudades o cruzar la frontera con Pakistán impunemente, ha demostrado que no todos los afganos los ven a los tan desfavorablemente como lo hacían la comunidad y la opinión pública internacional, y parecen ser especialmente populares entre un gran número de pashtunes que sintieron la pérdida de su influencia histórica en el país tras el advenimiento de Karzai y la Autoridad Interina.

\section{LAS ACCIONES DE LA CONTRAINSURGENCIA}

En diciembre de 2002, un terrorista suicida atacó la principal base de la Fuerza Internacional de Asistencia para la Seguridad -FIAS- en el país. Desde entonces, la FIAS ha obtenido resultados muy tímidos en su objetivo de disminuir la violencia y la amenaza insurgente, especialmente en la región de frontera con Pakistán.

En agosto de 2003, la OTAN oficialmente asumió el mando de la FIAS establecida por las Naciones Unidas en Kabul en 2002. Esta incluía algunas tropas norteamericanas, mientras otras permanecían organizadas separadamente para adelantar operaciones de contraterrorismo dentro

11. Este término surgió en 2003 en un artículo de The Economist, y ha ganado popularidad entre los observadores de la situación afgana. 
de la Operación Libertad Duradera. Entre 2002 y 2005, las tropas norteamericanas crecieron de 5.000 a 19.000 efectivos, pero la situación de seguridad empeoraba rápidamente. Así, y aunque la calidad de vida en general parecía mejorar como resultado de la supresión de las tremendas restricciones impuestas por los talibanes, la seguridad seguía la tendencia contraria. Para octubre de 2006, la FIAS había intentado asumir el control de la seguridad en todo Afganistán, dividiendo el territorio en cinco comandos; sin embargo, su capacidad real era limitada.

Las fuerzas de la FIAS han encontrado especial resistencia en las zonas del sur y el este, en donde los ataques y la violencia han crecido de manera sustancial. Los talibanes ha seguido una estrategia de guerra de guerrillas y atentados suicidas por medio de los cuales intenta aislar a Kabul y bloquear los abastecimientos de las tropas de la coalición. Para 2008, los talibanes habían comenzado a controlar las principales carreteras del país que conducen a la capital, generando difíciles condiciones de seguridad para los funcionarios del gobierno, trabajadores humanitarios, observadores y periodistas (Faramiñan et. al, 2009, p. 60), y evidenciando que la FIAS no tiene suficientes efectivos para controlar todo el territorio y hacer frente a la insurgencia de manera enérgica.

Se cree que los talibanes están operando con las mismas estrategias de los mujahideenes durante la ocupación soviética, manteniéndose firmes ante la gran cantidad de bajas que sufren y avanzando lentamente hacia Kabul en una maniobra de acorralamiento. En 2008, las tropas de la coalición sufrieron 294 muertes, 27\% más que en el año anterior, mientras que en 2009 las pérdidas se acercaron a los 500, similares a las sufridas en Irak durante los primeros años de la guerra. Para el 2012, se estima que el total de efectivos de la coalición muertos en el país sumaba 3.270, con 402 registradas sólo en ese año ${ }^{12}$.

La situación también empeoraba para la población civil. Si bien es cierto que las cifras de víctimas no se acercan al horror vivido en Irak ni aún en el peor momento, se trata de una situación ciertamente compleja. Se calcula que en los últimos seis años han muerto aproximadamente 14.728 civiles, 2.754 de ellos sólo durante el año pasado (Afghanistan Annual Report on Protection of Civilians in Armed Conflict 2012, 2013). Los talibanes se han concentrado en acciones como amenazas contra agentes y ciudadanos leales al gobierno, así como asesinatos ocasionales, que han eliminado o hecho huir a muchos afganos más proclives al gobierno de Karzai.

Los efectos de la guerra en Afganistán son evidentes en el entorno regional, especialmente en Pakistán, en donde una creciente violencia política y decenas de ataques suicidas han desafiado la capacidad del gobierno de mantener la ley y el orden. Además del impacto de la pérdida de profundidad estratégica garantizada con el mantenimiento de su Estado cliente tras el derrocamiento del régimen talibán, signos de lo que se denomina la "talibanización" del país son

12. Cifras tomadas de http://www.icasualties.org/.

EL RESURGIMIENTO DE LOS TALIBANES EN AFGANISTÁN 
perceptibles: los talibanes han tomado el control de muchas áreas tribales, forzando a los oficiales locales del gobierno a abandonarlas por seguridad. Estos también han impuesto su estricta versión del Islam, cerrando las escuelas para niñas, ordenando la reclusión de las mujeres en sus casas, prohibiendo los televisores y computadores o cerrando las barberías (Ghufran, 2008, p. 161). También han extendido sus actividades a ciudades importantes, incluyendo a Islamabad, y las operaciones militares paquistaníes han tenido poco éxito en controlarlos. Sin duda, la "Guerra contra el Terrorismo" incrementó la influencia de los talibanes en toda la región fronteriza.

Hamid Karzai ha afirmado en reiteradas oportunidades que las fuentes de la insurgencia talibán provienen de los campos de entrenamiento y las madrazas en Pakistán, siendo la zona de frontera su santuario (Ghufran, 2008, p. 162); sin embargo, se cree que el movimiento hoy recibe financiación externa de donantes individuales, y busca otras fuentes de recursos estableciendo el cobro de impuestos y rescates por secuestros en las áreas en las cuales son fuertes (Elias, 2009, p. 62). Para finales del 2005, una fuerza de solo 50.000 afganos, entre ejército y policía, fue asignada en todo el territorio; de este número, pocos eran competentes, bien equipados y confiables (O'Hanlon, 2010, p. 23); ello contribuye a comprender por qué los talibanes han podido restablecer su sistema judicial, especialmente en las áreas rurales, y mantienen gobiernos en la sombra en varias zonas de Afganistán.

Para el 2009, la OTAN estimaba que la insurgencia podía estar conformada por cerca de 25.000 combatientes, una cifra cercana a los niveles anteriores al 11-S (O'Hanlon, 2010, p. 26). Si bien han sido eliminados numerosos combatientes talibanes, esto se ha logrado a expensas de las vidas de cientos de civiles afganos, cuya rabia crece con cada bombardeo y ataque de las fuerzas de seguridad afganas y de la coalición en contra de viviendas, con los disparos contra civiles en las calles y puntos de control y, en general, con el fracaso de Karzai en manejar efectivamente todas las cuestiones relativas a la seguridad del país. No obstante, la violencia insurgente, y especialmente la de los talibanes, sigue devastando al país, mientras las posibilidades de terminación de la guerra aún no parecen cercanas.

\section{CONCLUSIONES}

A pesar de que algunos sectores asumían que el movimiento talibán no era más que una manifestación aberrante del extremismo religioso expresada como un fenómeno temporal en el marco de la estructura tribal pashtún, se ha constatado en los últimos años que se trata de un movimiento persistente y en constante transformación.

Luego de su derrota inicial por parte de las fuerzas de la coalición en Afganistán en el marco de la Guerra Mundial contra el Terrorismo, los talibanes han resurgido como una fuerza temida e influyente que ha podido recuperar gradualmente su influencia y capacidad de acción en 
diversas regiones del país. Los talibanes se ven a sí mismos como parte de un movimiento que combate por la justicia, que es capaz de llevar la seguridad que el gobierno no puede proveer, y que ofrece una alternativa de orden social en medio de las precarias condiciones prevalentes para la mayor parte de la población. Esto les ha proveído de apoyo popular, mayormente pashtún, que se basa principalmente en una afinidad ideológica y en la aversión hacia las fuerzas de ocupación extranjera, de quienes el gobierno de Karzai es considerado sólo un cliente.

En este contexto, es claro que una estrategia de contrainsurgencia que ignore las limitaciones del poder militar está destinada al fracaso. Desde 2009, y frente a la creciente influencia de los talibanes en varias regiones del país, el gobierno de Barack Obama ha impulsado un proceso de negociaciones para poner fin a una guerra que los Estados Unidos y el gobierno afgano están perdiendo. Esta iniciativa pretende desarrollar las herramientas políticas y militares necesarias para que los talibanes acepten la Constitución afgana, renuncien a la violencia y rompan sus lazos con al Qaeda.

Sin embargo, ni el gobierno afgano ni las fuerzas de la ocupación podrán terminar la guerra y estabilizar al país si los talibanes y sus bases de apoyo no perciben que pueden tener un espacio en la vida política afgana. Hasta hoy, los resultados de las conversaciones han sido pobres, en parte debidos a la precaria inclusión y falta de transparencia, pero más importante aún, porque parece haberse subestimado las profundas raíces, la heterogeneidad y la complejidad de la amenaza insurgente y del mismo movimiento talibán en Afganistán.

\section{REFERENCIAS}

- Afghanistan Annual Report on Protection of Civilians in Armed Conflict (2012). Recuperado de: http://unama.unmissions.org/Portals/UNAMA/Documents/UNAMA\%20POC\% 202011\%20Report_Final_Feb\%202012.pdf. 15 de marzo de 2013.

- Crews, R. D. \& Tarzi, A. (2008). Talibán and the Crisis of Afghanistan. Cambridge, MA: Harvard University Press.

- Elias, M. O. T. (2009). The resurgence of the Taliban in Kabul: Logar and Wardak. En: Giustozzi, A. Decoding the New Talibán: Insights from the Afghan Field. New York: Columbia University Press.

- Gasper, P. (2001). Afghanistan, the CIA, bin Laden, and the Taliban. Recuperado de: http://www.thirdworldtraveler.com/Afghanistan/Afghanistan_CIA_Talibán.html. 20 de abril de 2012.

- Ghufran, N. (2008). Afghanistan in 2007: A Bleeding Wound. Asian Survey, 48, 1, 154-163. 
- Giustozzi, A. (2010). Los grupos étnicos y la movilización política en Afganistán. Revista de Estudios Sociales, 37, 30-45.

- Giustozzi, A. (2009). Decoding the New Talibán: Insights from the Afghan Field. New York: Columbia University Press.

- Jones, S. G. (2008). Counterinsurgency in Afghanistan. Santa Monica, CA: RAND Corporation.

- Leigh, K. (April 3, 2012). Afghanistan Falls Apart. Foreign Policy. Recuperado de: http://www.foreignpolicy.com/articles/2012/04/03/afghanistan_falls_apart

- Maley, W. (2002). Afghanistan Wars. Gordonsville: Palgrave Macmillan.

- Maley, W. (Ed.) (1998). Fundamentalism reborn?: Afghanistan and the Talibán. New York: NYU Press.

- O'Hanlon, M. E. \& Sherjan, H. (2010). Toughing It Out in Afghanistan. Washington, DC: Brookings Institution Press.

- $\quad$ Rashid, A. (1999). The Taliban: Exporting Extremism. Foreign Affairs, 78, 6, 22-35.

- Rashid, A. (2002). Talibán: Islam, Oil and the New Great Game in Central Asia. London: I.B. Tauris.

- $\quad$ Rotberg, R. I. (2006). Building a New Afghanistan. Washington, DC: Brookings Institution Press.

- $\quad$ Roy, O. (2003). El islam mundializado. Barcelona: Bellaterra.

- Shinn, J. (2011) Afghan Peace Talks: A Primer. Santa Monica, CA: RAND Corporation.

- Sinno, A. (2008). Explaining the Taliban's Ability to Mobilize the Pashtuns. En Crews, R. y Tarzi, A. Taliban and the Crisis of Afghanistan. Cambridge, MA: Harvard University Press.

- $\quad$ Sirrs, J. (2001). The Taliban's International Ambitions. Middle East Quarterly, VIII, 3, 61-71. Recuperado de: http://www.meforum.org/486/the-talibáns-international-ambitions

Fuentes electrónicas:

- http://www.icasualties.org/ 